\title{
Spinal Dopaminergic Projections Control the Transition to Pathological Pain Plasticity via a $\mathrm{D}_{1} / \mathrm{D}_{5}$-Mediated Mechanism
}

\author{
Ji-Young V. Kim, ${ }^{1}$ Dipti V. Tillu, ${ }^{2}$ Tammie L. Quinn, ${ }^{3}$ Galo L. Mejia, ${ }^{1,2}$ Adia Shy, ${ }^{1}$ Marina N.K. Asiedu, ${ }^{1,2}$ Elaine Murad, ${ }^{1}$ \\ ${ }^{\circ}$ Alan P. Schumann, ${ }^{3}$ Stacie K. Totsch, ${ }^{3}$-Robert E. Sorge, ${ }^{3}$ Patrick W. Mantyh, ${ }^{1}$ Gregory Dussor, ${ }^{1,2}$ \\ and Theodore J. Price ${ }^{1,2}$ \\ ${ }^{1}$ Department of Pharmacology, University of Arizona, Tucson, Arizona 85721, ${ }^{2}$ School of Behavioral and Brain Sciences, University of Texas at Dallas, \\ Richardson, Texas 75080, and ${ }^{3}$ Department of Psychology, University of Alabama at Birmingham, Birmingham, Alabama 35294
}

\begin{abstract}
The mechanisms that lead to the maintenance of chronic pain states are poorly understood, but their elucidation could lead to new insights into how pain becomes chronic and how it can potentially be reversed. We investigated the role of spinal dorsal horn neurons and descending circuitry in plasticity mediating a transition to pathological pain plasticity suggesting the presence of a chronic pain state using hyperalgesic priming. We found that when dorsal horn neurokinin 1 receptor-positive neurons or descending serotonergic neurons were ablated before hyperalgesic priming, IL-6- and carrageenan-induced mechanical hypersensitivity was impaired, and subsequent prostaglandin $\mathrm{E} 2\left(\mathrm{PGE}_{2}\right)$ response was blunted. However, when these neurons were lesioned after the induction of priming, they had no effect on the $\mathrm{PGE}_{2}$ response, reflecting differential mechanisms driving plasticity in a primed state. In stark contrast, animals with a spinally applied dopaminergic lesion showed intact IL-6- and carrageenan-induced mechanical hypersensitivity, but the subsequent $\mathrm{PGE}_{2}$ injection failed to cause mechanical hypersensitivity. Moreover, ablating spinally projecting dopaminergic neurons after the resolution of the IL-6- or carrageenan-induced response also reversed the maintenance of priming as assessed through mechanical hypersensitivity and the mouse grimace scale. Pharmacological antagonism of spinal dopamine $D_{1} / D_{5}$ receptors reversed priming, whereas $D_{1} / D_{5}$ agonists induced mechanical hypersensitivity exclusively in primed mice. Strikingly, engagement of $D_{1} / D_{5}$ coupled with anisomycin in primed animals reversed a chronic pain state, consistent with reconsolidation-like effects in the spinal dorsal horn. These findings demonstrate a novel role for descending dopaminergic neurons in the maintenance of pathological pain plasticity.
\end{abstract}

Key words: chronic pain; descending modulation; dopamine; nociceptive plasticity; reconsolidation; substance $\mathrm{P}$

\section{Introduction}

Compelling evidence for similarities between cellular mechanisms involved in nociceptive sensitization and learning and memory has led to the emergence of the idea of "pain memory" encoded by pathological plasticity in pain circuits (Melzack et al., 2001; Ji et al., 2003; Asiedu et al., 2011; Bogen et al., 2012; DrdlaSchutting et al., 2012; Bonin and De Koninck, 2014). Neuromodulatory neurotransmitters exert a powerful influence over cellular plasticity in brain circuits and are crucial regulators of learning and memory in a wide variety of paradigms (GonzalezBurgos and Feria-Velasco, 2008). These same neurotransmitters

Received Aug. 19, 2014; revised March 4, 2015; accepted March 5, 2015.

Author contributions: J.-Y.V.K., R.E.S., P.W.M., G.D., and T.J.P. designed research; J.-Y.V.K., D.V.T., T.L.Q., G.L.M., A.S., M.N.K.A., E.M., A.P.S., and S.K.T. performed research;P.W.M. contributed unpublished reagents/analytic tools; J.-Y.V.K., D.V.T., R.E.S., G.D., and T.J.P. analyzed data; J.-Y.V.K., G.D., and T.J.P. wrote the paper.

Acknowledgements: This work was supported by The Rita Allen Foundation (TJP), NIH grants R01NS065926

(TJP), R01GM102575 (TJP and GD) and The University of Texas STARS program (TJP and GD).

The authors declare no competing financial interest.

Correspondence should be addressed to Theodore J Price, School of Behavioral and Brain Sciences, University of Texas at Dallas, J0 4.212, 800 West Campbell Road, Richardson, TX 75080. E-mail: theodore.price@utdallas.edu. DOI:10.1523/JNEUROSCI.3481-14.2015

Copyright $\odot 2015$ the authors $\quad 0270-6474 / 15 / 356307-11 \$ 15.00 / 0$ are well-known descending modulators of pain sensitivity (Fields et al., 1991). Descending pain modulators, arising primarily from the brainstem, can facilitate or inhibit acute pain, and lesions of these systems change the response of pain circuits to persistent inflammation or nerve injury (Ossipov et al., 2010). Investigations into the role of descending modulatory systems in the formation, modulation, and maintenance of pathological pain plasticity have revealed important insights into clinical pain disorders (Fields et al., 1991; Ossipov et al., 2010).

We used a mouse model of hyperalgesic priming (Aley et al., 2000) to study descending influences over the initiation and maintenance of pathological pain plasticity. An emerging view in the field is that the maintenance mechanisms of hyperalgesic priming, which persist for weeks or even months in mice and rats, may provide insights into how the acute to chronic pain transition happens (Reichling and Levine, 2009; Asiedu et al., 2011; Reichling et al., 2013; Price and Inyang, 2015). We studied three descending modulatory systems using targeted toxins: serotonergic $(5-\mathrm{HT})$ input to the spinal cord from nucleus raphe magnus, noradrenergic (NE) projections from the locus coeruleus, and dopaminergic (DA) projections from the hypothalamic A11 nucleus. Serotonin is thought to primarily promote pain signaling 
Table 1. Experimental compounds

\begin{tabular}{lllll}
\hline Experimental compounds & Vendor & Catalog number & Dose & Mechanism of action \\
\hline 5,7-DHT & Sigma-Aldrich & 37970 & $50 \mu \mathrm{g}$ (Sawynok et al., 1991; Sawynok and Reid, 1994) & Serotonergic toxin \\
6-OHDA-hydrobromide & Sigma-Aldrich & $\mathrm{H} 116$ & $50 \mu \mathrm{g}$, i.t. (Sawynok et al., 1991) & Catacholinergic toxin \\
6-OHDA-hydrochloride & Sigma-Aldrich & $\mathrm{H} 4381$ & $200 \mathrm{mg} / \mathrm{kg}$, i.p. (Minett et al., 2014) & Catacholinergic toxin \\
Anti-D $\beta$ H-SAP & Advanced Targeting Systems & $\mathrm{IT}-03$ & $5 \mu \mathrm{g}$ (Hayashida et al., 2012) & Adrenergic toxin \\
Anisomycin & Sigma-Aldrich & $\mathrm{A} 9789$ & $67.5 \mu \mathrm{g}$ (Bonin and De Koninck, 2014) & Ribosome Inhibitor \\
Desipramine & Sigma-Aldrich & $\mathrm{D} 3900$ & $25 \mathrm{mg} / \mathrm{kg}$ (Sawynok and Reid, 1994) & Norepinephrine reuptake transporter inhibitor \\
GBR12909 & Tocris Bioscience & 0421 & $40 \mathrm{mg} / \mathrm{kg}$ (Teicher et al., 1986) & Dopamine reuptake transporter inhibitor \\
SCH23390 & Tocris Bioscience & 0925 & $3.3 \mu \mathrm{g}$ (Shimizu et al., 2006) & D $_{1} / \mathrm{D}_{5}$ antagonist \\
SKF-82958 & Sigma-Aldrich & $\mathrm{C130}$ & $4.1 \mu \mathrm{g}$ (Shimizu et al., 2006) & $\mathrm{D}_{1} / \mathrm{D}_{5}$ agonist \\
Substance P-SAP (with blank-SAP) & Advanced Targeting Systems & $\mathrm{IT}-11$ & $300 \mathrm{ng}$ (Mantyh et al., 1997; Nichols et al., 1999) & Selective NK1 toxin \\
Sulpiride & Tocris Bioscience & 0895 & $3.5 \mu \mathrm{g}$ (Shimizu et al., 2006) & D2 antagonist \\
ZIP/Scrambled ZIP & Anaspec & 63361 & $10 \mu \mathrm{g}$ (Asiedu et al., 2011) & aPKC inhibitor \\
\hline
\end{tabular}

in the spinal dorsal horn through stimulation of presynaptic 5- $\mathrm{HT}_{3}$ receptors promotes pain (Suzuki et al., 2004a; Kim et al., 2014); however, other 5-HT mechanisms in the dorsal horn play an important role in pain inhibition (Lopez-Garcia, 2006; Bardin, 2011; Song et al., 2011). Descending norepinephrine promotes pain inhibition largely through activation of $\alpha_{2}$ subtype adrenoreceptors (Ossipov et al., 2010). Compared to norepinephrine and serotonin, relatively little is known about the descending influence of dopamine, but existing evidence supports analgesic mechanisms engaged by $\mathrm{D}_{2}$ receptors (Taniguchi et al., 2011) and pro-nociceptive effects via $D_{1} / D_{5}$ receptors (Yang et al., 2005). Based on their prominent role in regulation of spinal nociceptive circuits, we hypothesized that these descending modulatory pathways may govern the maintenance of hyperalgesic priming.

Here we describe a previously unknown role for descending dopaminergic control of pathological pain plasticity. We show that a spinal DA lesion prevents and reverses the maintenance of hyperalgesic priming via a $\mathrm{D}_{1} / \mathrm{D}_{5}$-mediated mechanism, whereas 5-HT or NE lesions are incapable of influencing established hyperalgesic priming. Our findings point out important differences in descending modulation of pain circuitry once pathological pain plasticity is established and elucidate novel dopaminergic mechanisms affording opportunities for potentially reversing pathological pain states.

\section{Materials and Methods}

Experimental animals. All procedures that involve use of animals were approved by the Institutional Animal Care and Use Committees of the University of Arizona, the University of Alabama at Birmingham, and the University of Texas at Dallas and were in accordance with International Association for the Study of Pain guidelines. All behavioral studies were conducted using male or female Institute of Cancer Research (ICR) mice weighing between 20 and $25 \mathrm{~g}$ (Harlan Laboratories). Mice were used in behavioral experiments starting 1 week after arrival at the animal facility at the University of Arizona School of Medicine, University of Alabama at Birmingham, or University of Texas at Dallas. Animals were housed with a $12 \mathrm{~h}$ light/dark cycle and had food and water available ad libitum.

Lesions. Neurokinin 1 receptor (NK1)-positive neuron lesion was done using substance P conjugated to saporin (SP-SAP; Mantyh et al., 1997; Nichols et al., 1999). Three hundred nanograms were injected intrathecally using the injection method described previously (Hylden and Wilcox, 1980). Serotonergic lesion was done by intrathecal administration of 5,7-dihydroxytriptamine (5,7-DHT, $50 \mu \mathrm{g}$ ) combined with intraperitoneal desipramine $(25 \mathrm{mg} / \mathrm{kg})$ to ensure preservation of $\mathrm{NE}$ neurons (Sawynok and Reid, 1994). Noradrenergic lesion was done in two ways: anti-dopamine $\beta$ hydroxylase $(\mathrm{D} \beta \mathrm{H})$ conjugated to saporin $(\mathrm{D} \beta \mathrm{H}-\mathrm{SAP}, 5 \mu \mathrm{g})$ was injected intrathecally or 6 hydroxy-dopamine hydrobromide (6-OHDA; $50 \mu \mathrm{g}$ ) was given intrathecally (Sawynok et al., 1991). Here, the dopamine reuptake blocker 1-[2-[bis-(4-fluorophenyl) methoxy] ethyl]-4-(3-phenylpropyl)piperazine dihydrochloride
(GBR12909; 40 mg/kg; Teicher et al., 1986) was administered intraperitoneally $30 \mathrm{~min}$ before 6-OHDA injection to block targeting of dopaminergic neurons. Spinal dopaminergic lesion was done by injecting 6-OHDA ( $50 \mu \mathrm{g}$, i.t.) with desipramine $(25 \mathrm{mg} / \mathrm{kg})$ given intraperitoneally (Sawynok et al., 1991). Finally a peripherally restricted dopaminergic lesion was done using intraperitoneal injection of 6-OHDA hydrochloride (200 mg/kg; Minett et al., 2014) preceded by desipramine $(25 \mathrm{mg} / \mathrm{kg}$, i.p.) to spare adrenergic neurons. All experimental compounds, doses, sources, and catalog numbers are described in Table 1.

Behavioral testing: mechanical withdrawal threshold and mouse grimace scale testing. Mechanical withdrawal threshold testing was conducted using the up-down method of Dixon with modification (Dixon, 1965; Chapman et al., 1985). Animals were placed in acrylic boxes with wire mesh floors and habituated for a minimum of $1 \mathrm{~h}$ before the measurement of mechanical withdrawal thresholds of the appropriate hindpaw using calibrated von Frey filaments (Stoelting). To establish hyperalgesic priming, we administered $0.1 \mathrm{ng}$ of recombinant human IL-6 (R \& D systems) in $25 \mu \mathrm{l}$ sterile $0.9 \% \mathrm{NaCl}$ saline or $1 \%$ carrageenan $(\mathrm{w} / \mathrm{v}$; Sigma-Aldrich) in $30 \mu \mathrm{l}$ sterile $\mathrm{H}_{2} \mathrm{O}$ into the left hindpaw with an intraplantar injection and measured their mechanical withdrawal thresholds at 3, 24, and $72 \mathrm{~h}$ after injection. Following complete resolution of the initial mechanical hypersensitivity, mice were again assessed for their mechanical withdrawal threshold and subsequently injected in the left hindpaw with $100 \mathrm{ng}$ of prostaglandin $\mathrm{E} 2\left(\mathrm{PGE}_{2}\right)$ (Cayman Chemical) in $10 \mu$ l of sterile $0.9 \%$ saline. Afterward, mechanical withdrawal thresholds were measured at 3 and $24 \mathrm{~h}$. For all intrathecal injections, drugs were administered in 5 or $10 \mu \mathrm{l}$ sterile $0.9 \%$ saline or water to animals anesthetized with isoflurane for no longer than $3 \mathrm{~min}$. For all intraperitoneal injections, drugs were dissolved in sterile saline and administered in 200 $\mu$ l volume.

The mouse grimace scale (MGS) was used to quantify affective aspects of pain in mice (Langford et al., 2010). We scored the changes in the facial expressions (using the facial action coding system) $3 \mathrm{~h}$ after intraplantar $\mathrm{PGE}_{2}$ injection.

The experimenters measuring mechanical withdrawal thresholds or scoring mouse facial expressions were always blinded to the experimental conditions. Mice were randomized to groups by a blinded experimenter, and mice of individual groups were never housed together (e.g., home cages were always mixed between experimental groups).

Perfusion and tissue collection. Mice were anesthetized with intraperitoneal ketamine $(80 \mathrm{mg} / \mathrm{kg})$ and xylazine $(12 \mathrm{mg} / \mathrm{kg})$ mixture and perfused transcardially with $30 \mathrm{ml}$ of $100 \mathrm{~mm}$ PBS, $\mathrm{pH}$ 7.4, with heparin (10 $\mathrm{U} / \mathrm{ml}$ ). Following the PBS perfusion, animals were fixed with $30 \mathrm{ml}$ of $4 \%$ paraformaldehyde or $4 \%$ formaldehyde $12.5 \%$ picric acid ( $\mathrm{pH} 6.9$ ) mixture. The spinal cord and/or brain was removed and further fixed in the same fixative overnight at $4^{\circ} \mathrm{C}$. Subsequently, the tissues were transferred to and incubated in $30 \%$ sucrose in $100 \mathrm{~mm} \mathrm{PBS}, \mathrm{pH} \mathrm{7.4,} \mathrm{for} 48 \mathrm{~h}$ at $4^{\circ} \mathrm{C}$. Once the tissues were cryoprotected, they were embedded in O.C.T. (Sakura Finetek) for sectioning on a cryostat. Transverse lumbar spinal cord sections were cut at $20 \mu \mathrm{m}$, whereas brain sections were cut at $30 \mu \mathrm{m}$ and stored at $-80^{\circ} \mathrm{C}$ before immunohistochemical procedures. 
Table 2. Antibodies used in this study

\begin{tabular}{llll}
\hline Antibody & Vendor & Catalog number & Dilution \\
\hline Anti-NeuN & Millipore & MAB377 & $1: 3000$ \\
Anti-dopamine $\beta$ hydroxylase & Millipore & AB1585 & $1: 10,000$ \\
Anti-neurokinin 1 receptor & Mantyh lab (Nichols et al., 1999) & & $1: 3000$ \\
Anti-tryptophan hydroxylase & Millipore & AB152 & $1: 3000$ \\
Anti-DAT & Millipore & MAB369 & $1: 1000$ \\
Isolectin B4 & Invitrogen & I21412 & $1: 2000$ \\
Anti-CGRP & Peninsula Laboratories & IHC 6006 & $1: 2000$ \\
Goat anti-mouse 546 & Invitrogen & A11030 & $1: 2000$ \\
Goat anti-rabbit 488 & Invitrogen & A11034 & $1: 2000$ \\
Donkey anti-mouse 555 & Invitrogen & A31570 & $1: 2000$ \\
Donkey anti-rabbit 488 & Invitrogen & A21206 & $1: 2000$ \\
Donkey anti-sheep Cy3 & Jackson Immunoresearch & $713-166-147$ & $1: 500$ \\
\hline
\end{tabular}

Immunohistochemistry and image acquisition. Tissue sections were washed three times with $100 \mathrm{~mm}$ PBS and permeabilized and blocked with 0.3 or $1 \%$ Triton X-100 in 100 mM PBS, pH 7.4, containing 3\% goat or donkey serum (depending on antibodies). For NeuN, tryptophan hydroxylase (TPH), tyrosine hydroxylase $(\mathrm{TH})$, dopamine reuptake transporter (DAT), calcitonin gene-related peptide (CGRP) immunoreactivity, and isolectin B4 (IB4) staining, tissue sections were incubated in permeabilization/blocking solution containing $0.1 \mathrm{M}$ PBS with $3 \%$ normal goat serum and $0.3 \%$ Triton X-100. For NeuN and NK1 double immunoreactivity, tissue sections were incubated in permeabilization/ blocking solution containing $0.1 \mathrm{M}$ PBS with $3 \%$ normal donkey serum and $1 \%$ Triton $\mathrm{X}-100$. For NeuN and $\mathrm{D} \beta \mathrm{H}$ immunoreactivity, the sections were incubated in permeabilization/blocking solution containing $0.1 \mathrm{~m}$ PBS with $3 \%$ goat serum and $1 \%$ Triton X-100. Antibody dilutions, sources, and catalog numbers are described in Table 2. Following permeabilization and blocking for $1 \mathrm{~h}$ at room temperature, primary antibodies were added for overnight incubation at $4^{\circ} \mathrm{C}$. After the primary antibody incubation, slides were washed with PBS three times and then incubated for $1 \mathrm{~h}$ with secondary antibody at room temperature. Slides were washed with PBS three times once the secondary incubation was completed and then mounted in ProLong Gold mounting media (P36930; Invitrogen). Tissues from all groups were processed together under identical conditions with the same reagents.

Confocal microscopy images were obtained with an Olympus FluoView 1200 single-photon confocal microscope. All images are presented as $z$-projections of $z$-stacks. Images were processed using Adobe Photoshop CS5.

Image correlation analysis. Image analysis was performed using an ImageJ plug-in called JACoP (Just Another Co-localization Plugin) provided by Bolte and Cordelières, (2006) (http://rsb.info.nih. gov/ij/plugins/track/jacop2.html) as described in their review. To determine DAT immunoreactivity in NeuN-positive cells, the intensity correlation analysis (ICA) of Li et al. (2004) was calculated for regions of interest (ROIs) in images collected from vehicle and drug treatment groups.

Data analysis and statistics. All data are presented as mean \pm SEM. Graphpad Prism Version 6 for Mac and PC was used for plotting graphs and statistical analysis. Statistical differences between groups were measured by two-way ANOVA with Bonferroni's post hoc test. The a priori level of significance was set at $95 \%$.

\section{Results}

\section{Hyperalgesic priming persists for weeks after a single exposure to IL- 6 or carrageenan}

We showed previously that IL-6 injection into the hindpaw of mice induces hyperalgesic priming (Asiedu et al., 2011). In this model, we inject IL- 6 or carrageenan in the left hindpaw followed by $\mathrm{PGE}_{2}$ injection $7 \mathrm{~d}$ later. In primed mice, the $\mathrm{PGE}_{2}$ injection causes mechanical hypersensitivity that lasts for at least $72 \mathrm{~h}$, whereas the injection promotes only a transient $(<1 \mathrm{~h})$ mechanical hypersensitivity in mice treated previously with vehicle (Fig. 1A). This dramatic response to a normally subthreshold stimulus after priming suggests the presence of neuroplasticity that was established and maintained at least for $7 \mathrm{~d}$ after the injection of the priming insult. Although $7 \mathrm{~d}$ allows for complete resolution of mechanical hypersensitivity from IL-6 or carrageenan injection before precipitation of priming by $\mathrm{PGE}_{2}$ injection, we questioned the "chronicity" of this model by asking whether these neuroplastic changes underlying hyperalgesic priming can persist beyond $7 \mathrm{~d}$. We sought to address this question by increasing the wait time between the priming insults and $\mathrm{PGE}_{2}$ injection. We found that $\mathrm{PGE}_{2}$ caused mechanical hypersensitivity when injected 3 weeks after the IL-6 or carrageenan treatment. Strikingly, IL-6 primed animals showed mechanical hypersensitivity to $\mathrm{PGE}_{2}$ injection even at 5 weeks after injection (Fig. $1 B$ ). The pathological pain plasticity underlying hyperalgesic priming may involve persistent alterations to spinal or descending pain circuitry induced by the hyperalgesic priming stimulus.

\section{NK1-positive spinal cord neurons are required for initiation of hyperalgesic priming, but not for its maintenance}

The persistence of maintenance mechanisms of hyperalgesic priming may underlie the neuroplasticity driving the transition to a pathological pain state (Reichling and Levine, 2009; Price and Ghosh, 2013). While existing evidence supports a role for plasticity in peripheral nociceptors (Reichling and Levine, 2009; Melemedjian et al., 2010; Asiedu et al., 2011; Bogen et al., 2012; Ferrari et al., 2013; Wang et al., 2013; Melemedjian et al., 2014) and in the spinal dorsal horn (Asiedu et al., 2011; Corder et al., 2013; Melemedjian et al., 2013) in models of hyperalgesic priming, here we sought to determine specific CNS determinants, including descending circuits, of the initiation and maintenance of hyperalgesic priming via selective targeting approaches.

The first group of neurons that we targeted was the neurokinin 1 (NK1) receptor-positive subset of dorsal horn projection neurons. These neurons are essential for the establishment of mechanical and thermal hypersensitivity in a wide range of preclinical pain models (Mantyh et al., 1997; Nichols et al., 1999). However, their role in sustaining nociceptive plasticity has not been explored. Therefore, we sought to determine whether NK1positive projection neurons mediate initiation and/or maintenance of hyperalgesic priming. First, we tested the effect of ablating NK1-postive neurons on the initial IL-6 response. The NK1-targeted toxin, SP-SAP, was injected intrathecally $14 \mathrm{~d}$ before the injection of IL- 6 to eliminate dorsal horn NK1 expressing neurons. We found that eliminating NK1-postive neurons before IL-6 injection completely prevented mechanical hypersensitivity induced by IL- 6 and prevented development of hyperalgesic priming as revealed by a lack of effect of subsequent $\mathrm{PGE}_{2}$ treatment in SP-SAP treated mice (Fig. 2A). In stark contrast to the initiation experiment, the same dose of SP-SAP had no effect when given after priming was fully established by IL- 6 or carrageenan injection $7 \mathrm{~d}$ before SP-SAP (Fig. $2 \mathrm{~B}, C$ ). We removed the spinal cord and assessed NK1 immunoreactivity $14 \mathrm{~d}$ after SPSAP or blank-SAP treatment. SP-SAP treatment eliminated dorsal horn NK1 staining (Fig. 2D). Hence, NK1-positive dorsal horn neurons are required for the initiation of hyperalgesic priming, but they are dispensable for its maintenance.

\section{IL-6 induces bilateral priming}

The striking findings with SP-SAP suggest two major possibilities for the maintenance mechanism of hyperalgesic priming: (1) reorganization of local dorsal horn circuits such that NK1-positive projection neurons are no longer needed for mechanical hypersensitivity once priming is established or (2) the recruitment of descending circuits from supraspinal locations, thereby bypass- 

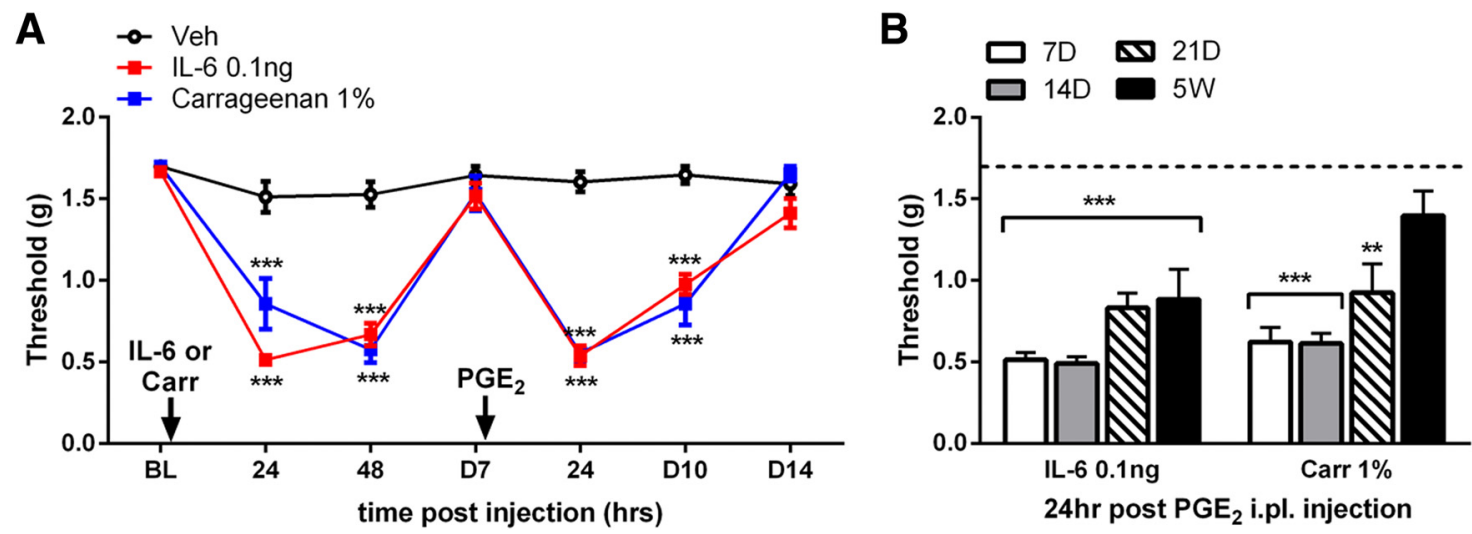

Figure 1. IL-6 and carrageenan can establish hyperalgesic priming that persists for weeks. $A$, Intraplantar injection of IL- 6 and carrageenan caused mechanical hypersensitivity that lasted for at least $48 \mathrm{~h}$. After a complete recovery from IL-6 and carrageenan, PGE $_{2}$ was injected into the same paw, which caused mechanical hypersensitivity only in animals exposed previously to IL-6 and carrageenan. $\boldsymbol{B}, \mathrm{PGE}_{2}$ injection precipitated mechanical hypersensitivity for at least 5 weeks after IL-6 and up to 3 weeks after carrageenan injection. ${ }^{* *} p<0.01 ;{ }^{* * *} p<0.001$ (two-way ANOVA with Bonferroni post hoc test). $n=6-8$ mice per group.
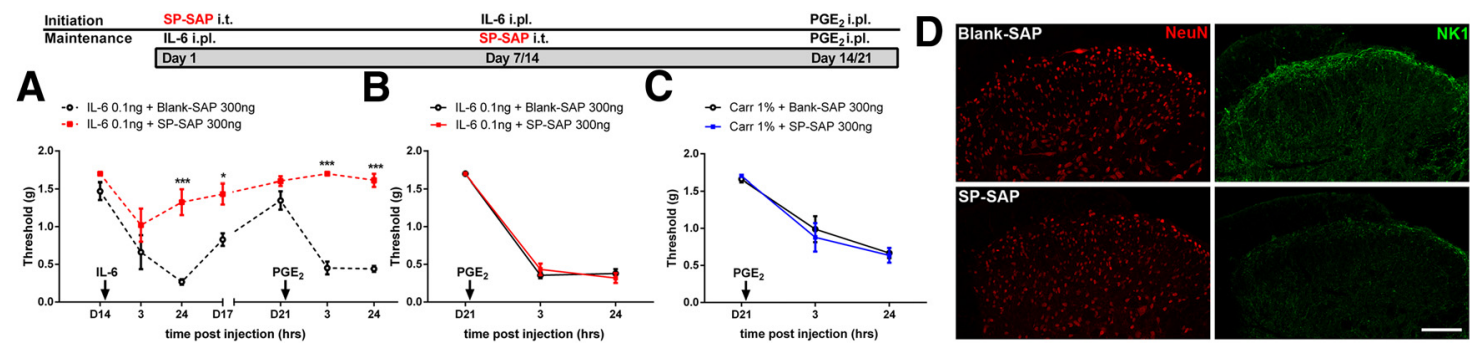

Figure 2. NK1 projection neurons differentially control the initiation and maintenance of hyperalgesic priming. $A$, Intrathecal injection of SP-SAP $14 \mathrm{~d}$ before IL-6 intraplantar injection prevented IL-6-induced mechanical hypersensitivity. $\boldsymbol{B}, \boldsymbol{C}$, SP-SAP, given $7 \mathrm{~d}$ after IL-6 $(\boldsymbol{B})$ or carrageenan $(\boldsymbol{C})$ injection failed to reverse hyperalgesic priming. $\boldsymbol{D}$, Spinal dorsal horn NK1 immunoreactivity was reduced by SP-SAP treatment. ${ }^{*} p<0.05 ;{ }^{* * *} p<0.001$ (two-way ANOVA with Bonferroni post hoc test). $n=6-8$ mice per group. Scale bar, $100 \mu \mathrm{m}$.

A $\rightarrow \quad$ IL-6 0.1ng + ipsilateral PGE 2
$\rightarrow$ IL-6 0.1ng + contralateral PGE

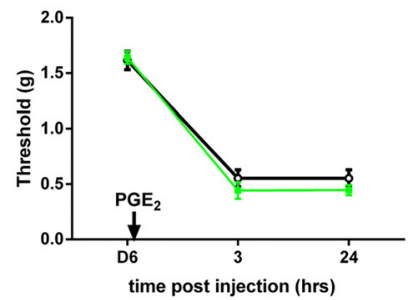

B

-o IL-6 $0.1 \mathrm{ng}+$ scramble-ZIP $10 \mu \mathrm{g}+$ contralateral PGE

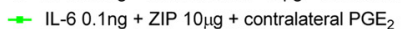

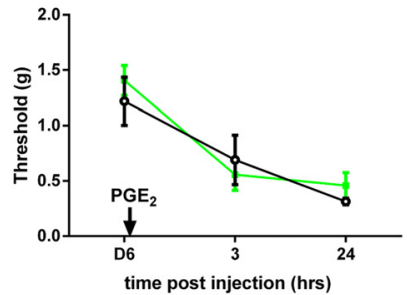

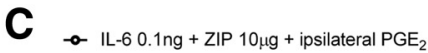

- IL-6 0.1ng + ZIP 10 $\mathrm{gg}+$ contralateral PGE

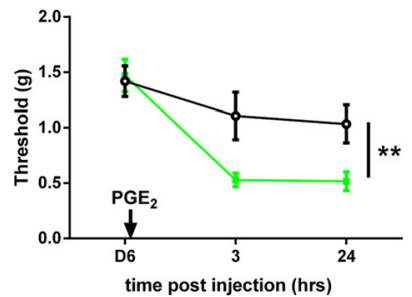

Figure 3. IL-6 induces bilateral priming. $A$, Intraplantar injection of $\mathrm{PGE}_{2}$ ipsilateral or contralateral to the previous IL-6 injection produced prolonged mechanical hyperalgesia. $n=4$ per group. $B$, Animals that received intrathecal injection of ZIP or scramble ZIP developed mechanical sensitive to contralateral injection of PGE 2 . $C_{1}$. The same dose of ZIP reversed ipsilateral priming, but not contralateral priming. $n=6$ mice per group $(\boldsymbol{B}, \boldsymbol{C}) .{ }^{* *} p<0.01$ (two-way ANOVA with Bonferroni post hoc test).

ing the involvement of NK1-positive neurons. To test these ideas, we assessed whether IL-6 produces contralateral priming. We first confirmed that $\mathrm{PGE}_{2}$ injection into the contralateral hindpaw produced robust priming equal to priming induced in the ipsilateral hindpaw (Fig. 3A). We then took advantage of our previous findings demonstrating that the atypical protein kinase $\mathrm{C}$ (aPKC) zeta inhibitory peptide (ZIP), given intrathecally, reverses hyperalgesic priming in the ipsilateral hindpaw of mice (Asiedu et al., 2011; Melemedjian et al., 2013). When IL-6 was given into the left hindpaw and animals were treated with intrathecal ZIP $(10 \mu \mathrm{g}) 2 \mathrm{~d}$ before $\mathrm{PGE}_{2}$ injection into the right hindpaw, a robust precipitation of priming was observed contralaterally, and this effect was unaffected by ZIP treatment (Fig. $3 B)$. On the other hand, consistent with our previous work (Asiedu et al., 2011; Melemedjian et al., 2013), when IL-6 was injected into the left hindpaw and ZIP was given $2 \mathrm{~d}$ before $\mathrm{PGE}_{2}$ injection into the left hindpaw, the maintenance of hyperalgesic priming was completely reversed even though ZIP treatment again had no effect on contralateral priming (Fig. $3 C$ ). Hence, ZIP's inability to abolish contralateral priming suggests that (1) contralateral priming is independent of spinal aPKC activity and (2) circuits with bilateral projections, such as descending modulatory inputs from the brainstem (Janss and Gebhart, 1988) and/or hypothalamus (Abdallah et al., 2013), may govern the maintenance of hyperalgesic priming.

Descending serotonergic projections are required for initiation but not maintenance of hyperalgesic priming Bilateral precipitation of priming suggests that hyperalgesic priming involves a descending modulatory circuit. To approach 

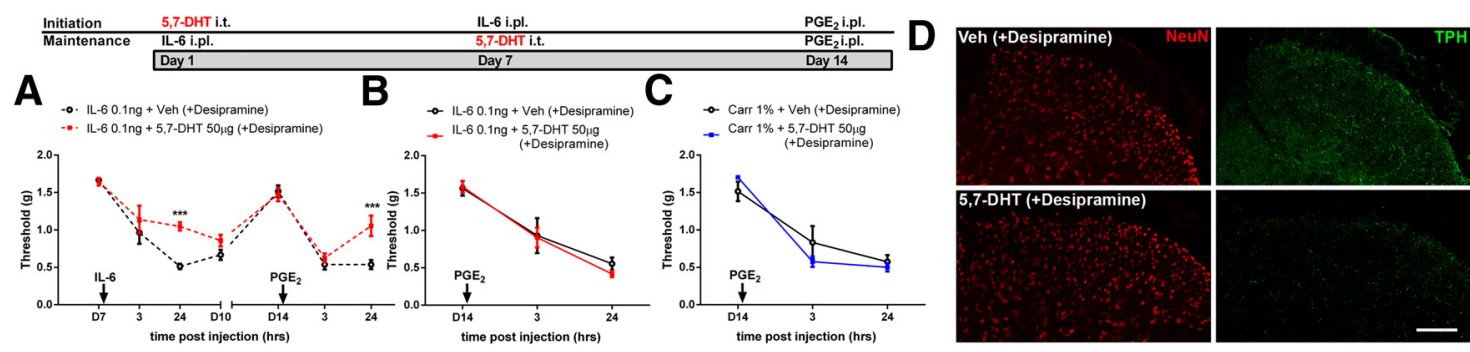

Figure 4. 5-HT neurons differentially influence the initiation and maintenance of hyperalgesic priming. A, A 5-HT lesion before IL-6 injection reduced the initial IL-6 response and hyperalgesic priming. $\boldsymbol{B}-\boldsymbol{D}$, Conversely, ablation of $5-\mathrm{HT}$ neurons after priming with IL-6 $(\boldsymbol{B})$ or carrageenan $(\boldsymbol{C})$ had no effect on the maintenance of priming but reduced TPH staining in the spinal dorsal horn (D). ${ }^{* * *} p<0.001$ (two-way ANOVA with Bonferroni post hoc test). $n=6-8$ mice per group. Scale bar, $100 \mu \mathrm{m}$.
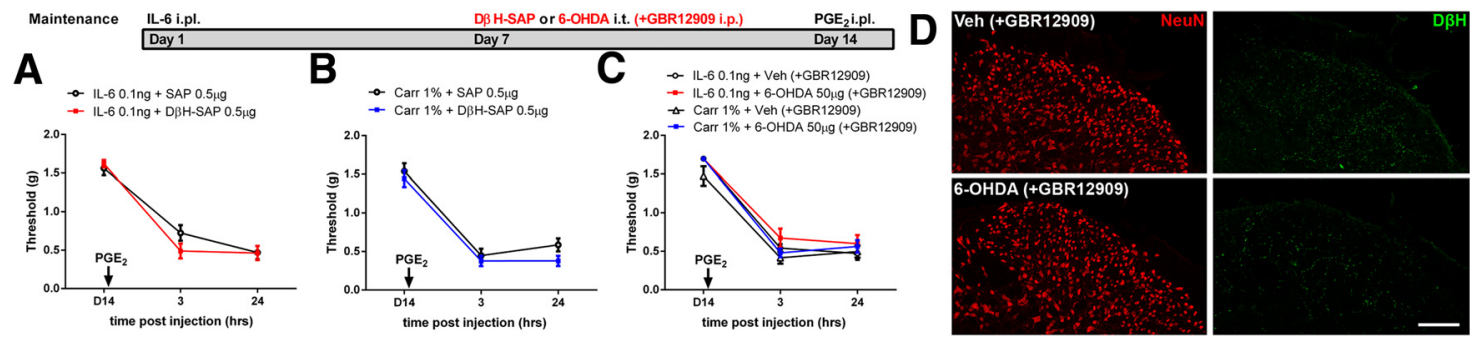

Figure 5. Ablation of NE neurons does not affect hyperalgesic priming. $A, D \beta H-S A P$ injection into the spinal cord $7 \mathrm{~d}$ after IL-6 treatment failed to influence hyperalgesic priming precipitated by intraplantar injection of $\mathrm{PGE}_{2} \cdot \boldsymbol{B}, \mathrm{D} \beta \mathrm{H}$-SAP also did not influence carrageenan-induced priming. C, Treatment with 6-OHDA and GBR12909 to induce a selective NE ablation in the spinal cord also did not affect hyperalgesic priming induced by either IL-6 or carrageenan. $\boldsymbol{D}, \mathrm{D} \beta \mathrm{H}$ immunoreactivity was reduced $7 \mathrm{~d}$ after treatment in the spinal dorsal horn of 6-0HDA and GBR12909-treated animals. $n=6-8$ mice per group. Scale bar, $100 \mu \mathrm{m}$.

this experimentally, we turned to 5-HT projections from the brainstem to the spinal cord because of their well-described role in nociceptive descending facilitation (Suzuki et al., 2002, 2004a,b; Kim et al., 2014), although serotonin has also long been described as having antinociceptive actions in the spinal dorsal horn (Roberts, 1984). Ablation of descending 5-HT inputs reduces pain hypersensitivity induced by peripheral nerve injury (Rahman et al., 2006), and current evidence supports a role of presynaptic $5-\mathrm{HT}_{3}$ receptors on afferent terminals in serotoninmediated descending facilitation (Kim et al., 2014). We tested the role of descending 5-HT neurons in initiation and maintenance of hyperalgesic priming using the selective 5-HT toxin, 5,7-DHT. First, we ablated 5-HT neurons by intrathecal administration of 5,7-DHT $(50 \mu \mathrm{g})$ combined with intraperitoneal desipramine $(25 \mathrm{mg} / \mathrm{kg}) 7 \mathrm{~d}$ before IL-6 injection. These mice demonstrated a blunted acute IL- 6 response and reduced $\mathrm{PGE}_{2}$ responses (Fig. $4 A$ ). Similar to the SP-SAP maintenance of priming experiment, the same dose of 5-HT toxin given after IL-6 or carrageenan injection failed to interfere with priming precipitated by $\mathrm{PGE}_{2}$ injection (Fig. $4 B, C$ ). In the spinal cords of vehicle-treated animals, TPH immunoreactivity was predominantly observed in the outermost lamina, with more diffuse expression in the deeper lamina. The toxin treatment strongly reduced TPH expression in these regions of the spinal dorsal horn $7 \mathrm{~d}$ after treatment (Fig. 4D). Therefore, consistent with previous studies (Suzuki et al., 2004a,b; Rahman et al., 2006; Kim et al., 2014), descending 5-HT neurons play a key role in mechanical hypersensitivity induced by an initial injury; however, these same neurons do not participate in the maintenance of hyperalgesic priming.

Descending noradrenergic projections are not required for maintenance of hyperalgesic priming

Our findings with 5,7-DHT rule out descending serotonin in the maintenance of hyperalgesic priming. Therefore, we continued our investigation with another well-known group of descending projecting neurons, NE neurons. Although descending NE neurons are thought to promote acute pain inhibition (Tracey and Mantyh, 2007; Ossipov et al., 2010) and protect against the emergence of neuropathic pain (De Felice et al., 2011), these same neurons may play a pain promoting role following injury. For example, NE toxin or local anesthetic injection into the locus coeruleus decreases cold and mechanical hypersensitivity in animals with established neuropathic pain (Brightwell and Taylor, 2009). Hence, we hypothesized that priming may require NE neurons for its maintenance. We chose only to examine the maintenance phase in these experiments due to the well-known antinociceptive role of descending NE modulation in acute nociception (Ossipov et al., 2010). Using the same experimental time course, we injected the selective NE toxin D $\beta \mathrm{H}-\mathrm{SAP}(0.5 \mu \mathrm{g})$ after IL-6- or carrageenan-induced mechanical hypersensitivity resolved. We observed that spinal treatment of $\mathrm{D} \beta \mathrm{H}-\mathrm{SAP}$ did not alter $\mathrm{PGE}_{2}$-induced responses (Fig. $5 A, B$ ). Alternatively, we targeted NE neurons with the catecholamine toxin 6-OHDA (50 $\mu \mathrm{g})$ given intrathecally. Here, the dopamine reuptake blocker GBR12909 (40 mg/kg) was administered systemically $30 \mathrm{~min}$ before 6-OHDA injection to block targeting of dopaminergic neurons. When this norepinephrine-selective targeting approach was used after IL-6- or carrageenan-induced mechanical hypersensitivity resolved, again, the full $\mathrm{PGE}_{2}$ response was intact (Fig. $5 C)$. A loss of spinal NE projections was confirmed by reduced $\mathrm{D} \beta \mathrm{H}$ immunoreactivity, which is observed throughout the dorsal horn with stronger expression in the superficial lamina (Fig. 5D). Hence, we conclude that NE descending projections are not required for the maintenance of hyperalgesic priming.

\section{Dopaminergic spinal projections are required for hyperalgesic priming}

We next investigated a possible role for DA pathways in maintenance of hyperalgesic priming. DA neurons are known to play a critical role in pain modulation in several areas of the CNS, in- 


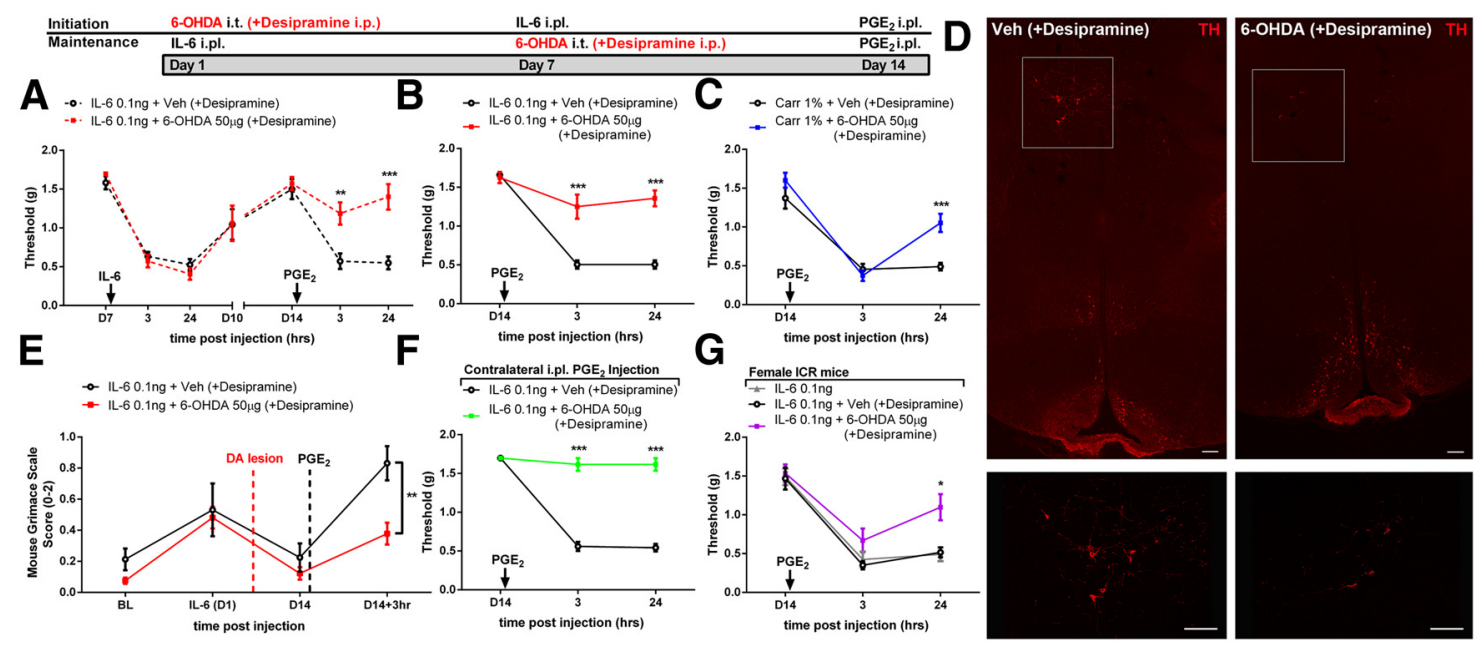

Figure 6. Dopaminergic neurons control hyperalgesic priming. $\boldsymbol{A}-\boldsymbol{C}$, DA lesion $7 \mathrm{~d}$ before IL-6 injection blocked hyperalgesic priming $(\boldsymbol{A})$, and DA lesion $7 \mathrm{~d}$ after IL-6 $(\boldsymbol{B})$ or carrageenan $(\boldsymbol{C})$ injection reversed the maintenance of hyperalgesic priming. $\boldsymbol{D}$, This spinally directed DA lesion reduced A11 hypothalamic DA neurons (6-OHDA + desipramine). $\boldsymbol{E}-\mathbf{G}, \mathrm{DA}$ lesion after IL-6 injection also attenuated the $P E_{2}$-induced increase in grimace scores in primed mice $(\boldsymbol{E})$, contralateral priming $(\boldsymbol{F})$, and priming in female mice $\left(\boldsymbol{G}, n=5\right.$ per group). $n=6-8$ mice per group in $\boldsymbol{A}-\boldsymbol{F}$. ${ }^{*} p<$ $0.05 ;{ }^{* *} p<0.01 ;{ }^{* * *} p<0.001$ (two-way ANOVA with Bonferroni post hoc test). Scale bar, $100 \mu \mathrm{m}$.

cluding the anterior cingulate cortex (López-Avila et al., 2004), nucleus accumbens (Chang et al., 2014), and spinal cord (Yang et al., 2005; Wei et al., 2009). DA projections to the spinal cord arise exclusively from the A11 area of the hypothalamus (Skagerberg et al., 1982), and these neurons modulate nociceptive processing in the dorsal horn (Charbit et al., 2009, 2011; Wei et al., 2009; Taniguchi et al., 2011). To determine whether these neurons play a role in hyperalgesic priming, we ablated DA neurons by injecting 6-OHDA (50 $\mu$ g, i.t.) with systemic injection of desipramine (25 $\mathrm{mg} / \mathrm{kg}$ ) to create a selective DA lesion. We observed that DA lesion had no effect on IL-6-induced mechanical hypersensitivity, but, strikingly, precipitation of priming with $\mathrm{PGE}_{2}$ failed in DA-lesioned mice (Fig. 6A). To examine whether DA could reverse hyperalgesic priming once it was established, we performed the DA lesion $7 \mathrm{~d}$ after IL-6 or carrageenan treatment. In stark contrast to NK1, 5-HT, and NE lesions after IL-6 or carrageenan injection, we found that spinal DA projections are required for the maintenance of a primed state (Fig. $6 B, C$ ). We confirmed that the DA toxin administered following IL-6 or carrageenan treatment reduced DA neurons in the hypothalamic A11 nucleus using TH staining (Fig. 6D).

Although these results demonstrate a clear role for descending DA neurons in mechanical hypersensitivity in hyperalgesic priming, it is not clear whether hyperalgesic priming also induces an affective pain state and/or if this is influenced by spinal dopamine. To assess both of these questions, we used the MGS (Langford et al., 2010). In mice treated previously with IL-6 who did not receive a DA spinal lesion, an increase in MGS score was observed $3 \mathrm{~h}$ following $\mathrm{PGE}_{2}$ injection (Fig. $6 E$ ). Lesioning DA neurons $7 \mathrm{~d}$ before $\mathrm{PGE}_{2}$ injection completely reversed this effect (Fig. 6E). Hence, spinal DA projections are required for mechanical hypersensitivity and affective pain responses in hyperalgesic priming.

The presence of bilateral hyperalgesic priming initially led us to investigate descending spinal projections in this experimental paradigm. Hence, we asked whether DA neurons were also responsible for IL-6-induced contralateral priming. Here the DA lesion after the initial IL- 6 insult also completely reversed maintenance of hyperalgesic priming when it was precipitated on the contralateral hindpaw (Fig. $6 F$ ).
Our finding shows a clear role of dopamine in hyperalgesic priming in male mice. Sexual dimorphic effects have been observed in hyperalgesic priming models (Joseph et al., 2003). First, we observed that IL-6-induced priming is robust in female ICR mice (Fig. 6G), similar to reports with carrageenan in this strain (Wang et al., 2013). We then asked whether a DA lesion also reverses hyperalgesic priming in female mice. We observed a similar reversal of hyperalgesic priming in female mice after the 6-OHDA (+desipramine) treatment (Fig. 6G).

While we confirmed a reduction of TH-immunoreactive A11 neurons $7 \mathrm{~d}$ after the spinally applied DA lesion, we sought to further validate our findings by examining changes in the expression of dopaminergic nerve endings in the spinal cord using the DA lesion approach. We took spinal cords from mice $7 \mathrm{~d}$ after 6-OHDA (+ desipramine) treatment and assessed expression of the dopamine reuptake transporter. We saw that while spinal cords from vehicle-treated animals showed a strong DAT immunoreactivity around large neurons located in the lateral part of deeper lamina (Fig. 7A, insets), DA lesion led to a significant reduction of DAT immunoreactivity in this region (vehicle, $0.27 \pm 0.041$; DA lesion, $0.17 \pm 0.020 ; n=6 ; p=0.0286$, Student's $t$ test; Fig. 7A). This demonstrates that the spinal 6-OHDA (+desipramine) treatment not only leads to the loss of dopaminergic neurons in A11, but also reduces DAT expression locally in the spinal cord. Additionally, we failed to see any changes in the expression of other monoamine neurotransmitter enzymes (TPH and $\mathrm{D} \beta \mathrm{H}$ ), or CGRP-positive peptidergic or IB4-positive nonpeptidergic nerve endings in outer lamina (Fig. $7 B$ ). These findings support a highly selective action of 6-OHDA (+desipramine) in creating a spinal DA lesion and indicate its lack of disturbance of primary afferent endings in the spinal dorsal horn (Fig. 7B).

Although we have extensively confirmed the selectivity of our spinal DA lesion approach, it is still possible that this intrathecal treatment led to destruction of DA neurons outside the CNS. For example, there are some suggestions that a subpopulation of small DRG neurons are dopamine positive (Brumovsky et al., 2006). To exclude a possible contribution of these neurons to the lesion phenotype observed here, we administered systemic desipramine $(25 \mathrm{mg} / \mathrm{kg})$ followed $30 \mathrm{~min}$ later by systemic 6-OHDA 

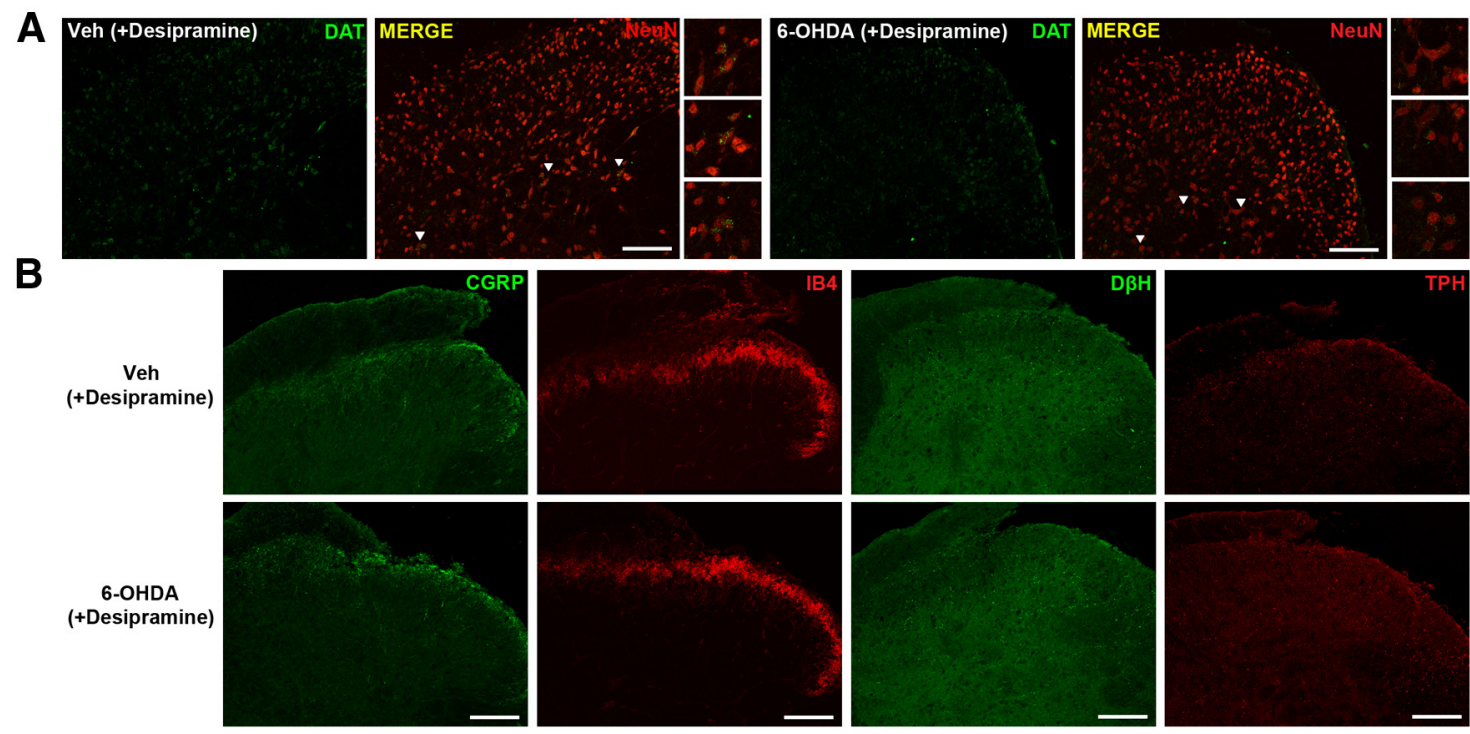

Figure 7. 6-OHDA (+ desipiramine)-directed DA lesion is highly selective for dopamine. $A, B$, Spinal DA lesion (6-OHDA + desipramine) significantly reduced DAT immunoreactivity $7 \mathrm{~d}$ after the treatment $(\boldsymbol{A})$ but did not disrupt $(\boldsymbol{B})$ other monoamine neurotransmitters (TPH and D $\beta H$ ) or primary ( fiber marker (CGRP and IB4) expression. Images are representative of $n=3$ mice per group. Scale bar, $100 \mu \mathrm{m}$.
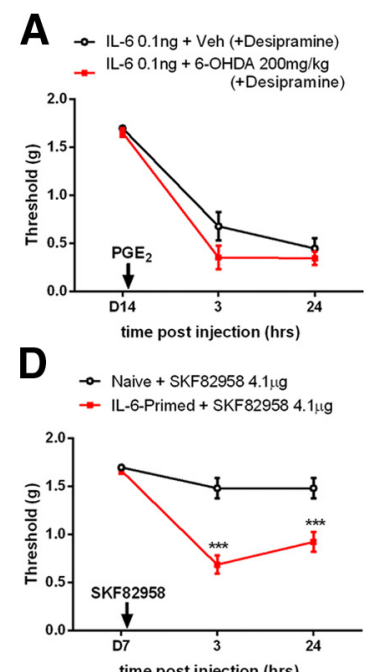

B

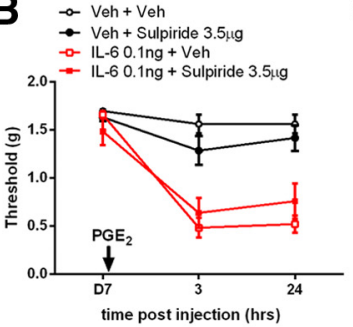

E

- Naive + SKF82958 4.1.ug

- Carr-Primed + SKF82958 4.1 $\mu \mathrm{g}$

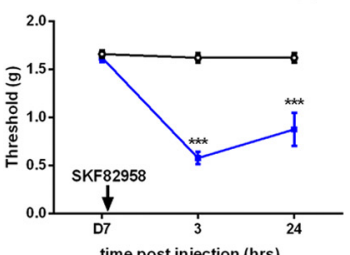

Ci

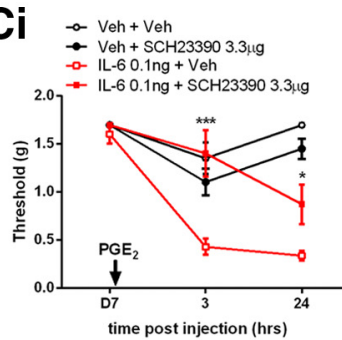

$\mathbf{F}$

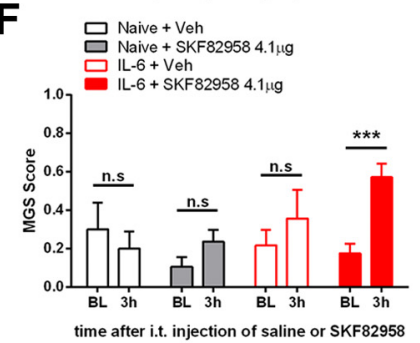

ii

-o. IL-6 0.1ng + Veh

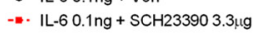

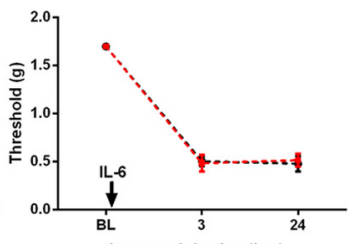

time post injection (hrs)

Figure 8. $\quad D_{1} / D_{5}$ receptors mediate hyperalgesic priming. $A$, A peripherally restricted DA lesion $7 \mathrm{~d}$ after IL-6 injection did not interfere with maintenance of hyperalgesic priming precipitated by $\mathrm{PGE}_{2}$ injection on day 14 after IL-6. $\boldsymbol{B}$, $\boldsymbol{C}$, Spinal injection of the $\mathrm{D}_{2}$ antagonist sulpiride at the time of $\mathrm{PGE}_{2}$ injection did not affect hyperalgesic priming $(\boldsymbol{B})$, whereas the D1/D5 antagonist SCH23380 blocked $\mathrm{PGE}_{2}$ precipitation of priming $(\boldsymbol{C C})$. Cii, The $\mathrm{D}_{1} / \mathrm{D}_{5}$ antagonist $\mathrm{SCH} 23380$ given spinally at the time of IL-6 injection failed to influence IL-6-mediated acute mechanical hypersensitivity. $\boldsymbol{D}$, Intrathecal injection of the $D_{1} / D_{5}$ agonist SKF82958 precipitated mechanical hypersensitivity only in animals primed with IL-6.n $=6-8$ mice per group. The experiment in $\boldsymbol{D}$ was performed with male and female mice. $\boldsymbol{E}$, Intrathecal injection of the $D_{1} / D_{5}$ agonist SKF82958 precipitated mechanical hypersensitivity only in animals primed with carrageenan. $n=6-8$ mice per group. $\boldsymbol{F}$, Intrathecal injection of the $D_{1} / D_{5}$ agonist SKF82958 induced grimacing only in mice previously exposed to IL- 6 compared to baseline measures taken $3 \mathrm{~h}$ before intrathecal injection. Mice received IL-6 or vehicle (Veh) (naive) into the hindpaw 7 d previously. Naive + veh, $n=3$; naive + SKF82958, $n=4$; IL-6 + veh, $n=6$; IL-6 + SKF82958, $n=10$. ${ }^{*} p<0.05 ;{ }^{* *} p<0.01 ;{ }^{* * *} p<0.001$ (two-way ANOVA with Bonferroni post hoc test).

(200 mg/kg), which does not readily cross the blood-brain barrier in adult rodents (Kostrzewa and Jacobowitz, 1974), to mice primed previously with IL-6. Seven days later, this systemic 6-OHDA treatment had no effect on $\mathrm{PGE}_{2}$-induced mechanical hypersensitivity in primed mice (Fig. $8 A$ ), ruling out an effect of DA lesion outside the CNS.

Recruitment of a $D_{1} / D_{5}$-dependent spinal mechanism for the maintenance of hyperalgesic priming

Our results show that a spinally directed DA lesion prevents and reverses plasticity responsible for the maintenance of hyperalge- sic priming. This suggests an active role of A11 DA projections in plasticity leading to pathological pain plasticity. We sought to determine which spinal DA receptors were responsible for this effect. We first examined $D_{2}$ receptors with the selective antagonist sulpride. Sulpride $(3.5 \mu \mathrm{g})$ was injected intrathecally at the time of $\mathrm{PGE}_{2}$ administration in animals primed with IL-6. Sulpride failed to modulate $\mathrm{PGE}_{2}$-induced mechanical hypersensitivity (Fig. $8 B$ ). In contrast, the $\mathrm{D}_{1} / \mathrm{D}_{5}$ antagonist $(R)$ - (+)-7-chloro-8-hydroxy-3-methyl-1-phenyl-2,3,4,5tetrahydro- $1 \mathrm{H}$-3-benzazepine hydrochloride (SCH23390; 3.3 $\mu \mathrm{g})$ given intrathecally at the time of $\mathrm{PGE}_{2}$ injection attenuated 

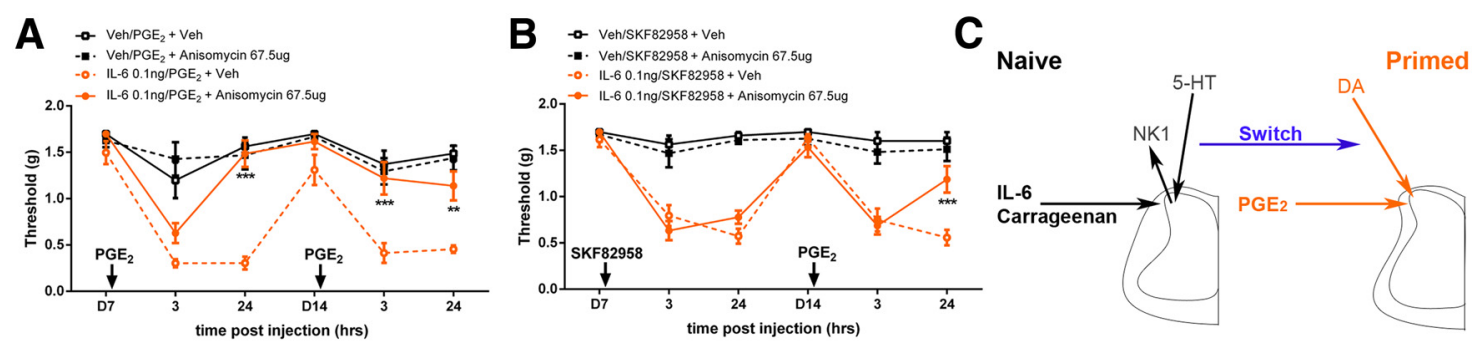

Figure 9. Precipitation of hyperalgesic priming renders the maintenance phase reversible by protein synthesis inhibition. $\boldsymbol{A}$, In IL-6 primed mice, anisomycin intrathecal injection paired with intraplantar $\mathrm{PGE}_{2}$ injection rapidly reversed the maintenance of hyperalgesic priming. $B$, Spinal injection of anisomycin at the time of $\mathrm{D}_{1} / \mathrm{D}_{5}$ agonist treatment in primed animals likewise reversed the maintenance of hyperalgesic priming when mice were subsequently challenged with intraplantar $\mathrm{PGE}_{2}$. C, Schematic illustrating plasticity mechanisms mediating maintenance of hyperalgesic priming. Acute pain plasticity induced by IL-6 or carrageenan requires NK1-positive projection neurons and descending 5-HT neurons for its full expression. However, following the transition to a primed state, neither NK1-positive nor serotonergic neurons are required for the continued presence of $\mathrm{PGE}_{2}$ precipitation of priming. Instead, descending dopaminergic input to spinal $D_{1} / D_{5}$ receptors controls the maintenance phase of hyperalgesic priming. $n=5-8$ mice per group. All experiments were performed with male and female mice. ${ }^{* *} p<0.01$; ${ }^{* * *} p<0.001$ (two-way ANOVA with Bonferroni post hoc test).

mechanical hypersensitivity (Fig. 8Ci). On the other hand, mirroring the effect observed with a spinally directed DA lesion given before IL-6 injection (Fig. $6 A$ ), the $D_{1} / D_{5}$ antagonist given at the time of IL-6 injection was completely without effect (Fig. 8Cii). Hence, differential $D_{1} / D_{5}$-mediated mechanisms contribute to pain plasticity in the initiation versus maintenance of hyperalgesic priming. Since a $D_{1} / D_{5}$ antagonist blocks precipitation of priming, we hypothesized that a $\mathrm{D}_{1} / \mathrm{D}_{5}$ agonist should do the opposite, even in the absence of $\mathrm{PGE}_{2}$ injection. Spinal injection of $\mathrm{D}_{1} / \mathrm{D}_{5}$ agonist in IL-6-primed animals precipitated mechanical hypersensitivity lasting for $24 \mathrm{~h}$ in male and female mice, whereas naive animals were completely unaffected (Fig. 8D). This effect was also observed in mice primed previously with carrageenan (Fig. 8E). Moreover, in mice treated with IL-6 $7 \mathrm{~d}$ previously, intrathecal injection of the $\mathrm{D}_{1} / \mathrm{D}_{5}$ agonist induced a significant increase in grimace scores at $3 \mathrm{~h}$ after injection, while a similar effect was not observed in control groups (Fig. $8 F$ ). We conclude that $D_{1} / D_{5}$ receptors regulate nociceptive responses exclusively in mice that have transitioned to a state of pathological pain plasticity.

To assess $\mathrm{D}_{1}$ and $\mathrm{D}_{5}$ receptor expression in the lumbar spinal dorsal horn, we examined the GENSAT database (gensat.org) for mice expressing reporter genes via the Drd1 and Drd5 loci (Schmidt et al., 2013). Drd1-driven enhanced green florescent protein (EGFP) expression is found throughout the spinal dorsal horn and localizes to neurons. Drd5-driven expression of EGFP was also found throughout the spinal dorsal horn, with strong neuronal expression in outer lamina and in deep dorsal horn. Previous work using in situ hybridization on mouse spinal cord for $D_{1}$ and $D_{5}$ mRNA found neuronal expression in dorsal and ventral horn for both receptors, with stronger expression for $\mathrm{D}_{5}$ receptor mRNA (Zhu et al., 2007), consistent with the GENSAT database. Based on these findings, we conclude that $D_{1} / D_{5}$ receptors are found throughout the spinal dorsal horn with a neuron-specific expression pattern and more prominent $\mathrm{D}_{5}$ receptor expression suggested by reporter mouse EGFP expression analysis.

\section{Activation of spinal $D_{1} / D_{5}$ receptors is permissive for pain reconsolidation}

We showed previously that while spinally applied translation inhibitors prevent hyperalgesic priming if they are coupled with the initial priming stimulus (e.g., IL-6), their administration during the maintenance phase has no effect on hyperalgesic priming (Asiedu et al., 2011). This finding parallels effects on early versus late phase hippocampal long-term potentiation (LTP), where protein synthesis inhibitors prevent the transition from early to late LTP but are not capable of reversing established late LTP (Abraham and Williams, 2008). Interestingly, late spinal LTP is also not reversed by protein synthesis inhibitors unless it is paired with a second tetanic stimulation at $\mathrm{C}$-fiber strength (Bonin and De Koninck, 2014). Remarkably, this effect can be mimicked behaviorally, suggesting a spinal mechanism of pain reconsolidation (Bonin and De Koninck, 2014), which parallels the classical observations in aversive memory paradigms with anisomycin injection paired with memory reactivation (Debiec et al., 2002). We therefore asked whether a reconsolidation-like effect can be observed in hyperalgesic priming models. Indeed, intrathecal injection of anisomycin $(67.5 \mu \mathrm{g})$ coupled with $\mathrm{PGE}_{2}$ injection into the hindpaw led to a reversal of mechanical hypersensitivity compared to vehicle-treated mice, and a subsequent response to $\mathrm{PGE}_{2}$ was completely absent (Fig. 9A). We reasoned that spinal injection of a $\mathrm{D}_{1} / \mathrm{D}_{5}$ agonist should also open a pain reconsolidation window, similarly to $\mathrm{PGE}_{2}$ injection. Although mice treated with SKF82958 with and without anisomycin all developed mechanical hypersensitivity following intrathecal drug administration, the subsequent response to $\mathrm{PGE}_{2}$ was markedly reduced at $24 \mathrm{~h}$ (and not different from unprimed mice) in mice that previously received anisomycin coupled with agonist (Fig. 9B). Based on these findings, reconsolidation of a spinal, translation-dependent pain memory trace occurs in hyperalgesic priming, and this can be induced by afferent stimulation or by activating $D_{1} / D_{5}$ receptors.

\section{Discussion}

Our findings support the following primary conclusions: (1) spinal NK1-positive and descending 5-HT neurons are required for establishing hyperalgesic priming but are dispensable for its maintenance; (2) NE neurons are not required for the maintenance of hyperalgesic priming; (3) descending DA neurons are required for the initiation and maintenance of hyperalgesic priming; (4) DA effects on hyperalgesic priming are $\mathrm{D}_{1} / \mathrm{D}_{5}$ receptor dependent; and (5) a reconsolidation-like process occurs in hyperalgesic priming, and spinal $D_{1} / D_{5}$ receptors engage this mechanism. These findings elucidate a novel role for spinal DA projections in the development and maintenance of pathological pain states.

Previous findings have demonstrated the involvement of dopamine in pain modulation, but clinical observations and preclinical data offer an unclear interpretation of dopamine's role in pain. In humans, dopaminergic neurotransmission and/or dopamine receptors are altered in fibromyalgia (Wood et al., 2007), burning mouth syndrome (Hagelberg et al., 2003b), and atypical 
facial pain (Hagelberg et al., 2003a). In healthy human volunteers, depletion of DA precursors or $\mathrm{D}_{2}$ antagonism fails to change acute sensory aspects of pain (Becker et al., 2013; Tiemann et al., 2014), but selectively modulates aspects of pain unpleasantness (Tiemann et al., 2014). In preclinical models, there is evidence for antinociceptive effects of dopamine via $\mathrm{D}_{2}$ receptor agonists in acute inflammatory pain (Gao et al., 2001), and stimulation of the $\mathrm{A} 11$ nucleus leads to a $\mathrm{D}_{2}$-dependent suppression of dorsal horn neuron activity (Charbit et al., 2009). On the other hand, activation of spinal $\mathrm{D}_{1} / \mathrm{D}_{5}$ receptors induces LTP in dorsal horn neurons receiving C-fiber input (Yang et al., 2005). Taking into account our findings, a possible interpretation arising from these collective results is that dopamine plays a specialized role in certain forms of pain plasticity that are most salient in persistent pain conditions. Our experiments are in line with this idea, as a DA lesion before the priming insult had no effect on acute mechanical hypersensitivity, but completely blocked the development of hyperalgesic priming. Likewise, removal of dopamine after the priming stimulus completely reversed hyperalgesic priming, both its evoked and affective manifestations and its bilaterality, again consistent with a need for descending DA input to maintain this state of nociceptive plasticity. Further work is required to understand how the maintenance mechanism of priming recruits descending $D_{1} / D_{5}$ dopaminergic signaling pathways and what their downstream targets are in this context; however, it is clear that these receptors are expressed in deep spinal dorsal horn neurons with prominent D5 expression in that area (gensat.org; Zhu et al., 2007). We cannot completely exclude a bilaterally projecting dopaminergic population of neurons intrinsic to the spinal cord as a possible mechanism to explain our observations (Skagerberg et al., 1982; Koltzenburg et al., 1999).

Our work indicates a critical function for $\mathrm{D}_{1} / \mathrm{D}_{5}$ receptors in plasticity underlying hyperalgesic priming. $\mathrm{D}_{1} / \mathrm{D}_{5}$ antagonism selectively blocked mechanical hypersensitivity in primed animals, and, conversely, $D_{1} / D_{5}$ stimulation induced mechanical hypersensitivity exclusively in primed mice. Dopamine plays a key role in modulation of synaptic plasticity throughout the CNS, primarily through a postsynaptic action at $D_{1} / D_{5}$ receptors (Hansen and Manahan-Vaughan, 2014). In line with effects in other CNS regions, recording from wide dynamic range neurons in the spinal dorsal horn upon slice application of $\mathrm{D}_{1} / \mathrm{D}_{5}$ agonist showed a slowly developing, protein synthesis-dependent LTP (Yang et al., 2005). We hypothesize that this $D_{1} / D_{5}$-dependent form of plasticity plays a crucial role in hyperalgesic priming allowing a normally subthreshold nociceptive input to the spinal cord to produce mechanical hypersensitivity and affective components of pain. Our finding that spinal application of $\mathrm{D}_{1} / \mathrm{D}_{5}$ agonist, in the presence of protein synthesis inhibition, leads to a reversal of the prolonged effect of $\mathrm{PGE}_{2}$ injection in primed mice supports this idea. In this model, activation of $D_{1} / D_{5}$ receptors would be capable of inducing a labile state in potentiated synapses that can be reversed by protein synthesis inhibition. This is consistent with reconsolidation theories of memory storage (Debiec et al., 2002) and with the recent demonstration of a reconsolidationlike effect in the spinal dorsal horn (Bonin and De Koninck, 2014), which we demonstrate can be induced even after a transition to a state of pathological pain plasticity. We note that the behavioral manifestations of disruption of different signaling mechanisms led to disparate results at the $3 \mathrm{~h}$ post-PGE $\mathrm{P}_{2}$ time point, which probably reflects differences in early versus late mechanisms of plasticity in hyperalgesic priming. Nevertheless, we observed consistent effects at the $24 \mathrm{~h}$ time point across our manipulations. We feel this time point is the most relevant because it reliably represents a prolonged pain phenotype induced by hyperalgesic priming.

The differential contribution of peripheral versus central mechanisms in the maintenance of pathological pain plasticity underlying hyperalgesic priming is not clearly delineated. Our previous work and work by other groups showed that peripheral translation blockade prevented (Melemedjian et al., 2010; Asiedu et al., 2011) and abolished hyperalgesic priming (Ferrari et al., 2013), thereby demonstrating the presence of a translationdependent neuroplasticity established in primary afferents during hyperalgesic priming. Other findings, including ours here, suggest that hyperalgesic priming is established bilaterally (Jasper and MacNeil, 2012), indicating that peripheral plasticity is not a requirement for priming and that central plasticity alone is permissive for hyperalgesic priming. In our view, these collective findings more convincingly argue for neuroplasticity in both peripheral and central compartments, and in the absence of either one, priming can be disrupted. An important factor, however, is targeting of the correct mechanism, at the correct time for reversal of the plasticity mechanism. In this work, we discovered dopamine and its action on $D_{1} / D_{5}$ receptor subtypes as a critical factor mediating the central plasticity of hyperalgesic priming. We also identified DAT-immunoreactive spinal projections as mediators of this DA-lesion phenotype and confirmed that our lesion approach is independent of damage to peripheral C-fiber neurons. Therefore, postsynaptic targets of these DATimmunoreactive projections are likely loci of the neuroplastic changes induced by hyperalgesic priming. Future work will strive to identify these neurons in more detail.

Our results demonstrate that NK1-postive projection neurons in the spinal cord are not required for the maintenance of hyperalgesic priming. NK1-posive neurons are crucial for thermal and mechanical hypersensitivity caused by nociceptor activation, inflammation, and nerve injury (Mantyh et al., 1997; Nichols et al., 1999; Suzuki et al., 2002). In line with these studies, we saw that the ablation of NK1-positive neurons before IL-6 injection profoundly alleviated mechanical hypersensitivity and blocked the development of hyperalgesic priming. In stark contrast, we found that when these neurons were lesioned after the resolution of the acute IL-6 or carrageenan response, animals showed full-blown precipitation of hyperalgesic priming. This finding indicates that NK1-positive neurons are not required for pain plasticity if they are ablated after a transition to chronic pain is established. The implications of this finding challenges our previous understanding of the types of ascending sensory pathways that are critical in transmission of nociceptive signals and suggests the possibility that the engagement of other ascending fiber pathways are more salient upon transition to a state of pathological pain plasticity. Moreover, if cellular mechanisms of pain plasticity in human chronic pain states are appropriately modeled by the maintenance phase of hyperalgesic priming models, our data are consistent with the failure of NK1 antagonists for the treatment of many different types of chronic pain conditions (Goldstein et al., 2000; Sindrup et al., 2006).

5-HT and NE descending modulatory circuits have received a great deal of attention in the context of inflammatory- and nerve injury-induced pain (Suzuki et al., 2004a,b; Rahman et al., 2006; Tracey and Mantyh, 2007; De Felice et al., 2011; Kim et al., 2014). These modulatory circuits play a key role in the development and maintenance of chronic neuropathic pain (Ossipov et al., 2010; De Felice et al., 2011). However, paralleling SP-SAP experiments, when the ablation of 5-HT neurons took place after the establish- 
ment of hyperalgesic priming, the subsequent $\mathrm{PGE}_{2}$ response was fully intact. Why is ablation of 5-HT neurons effective in alleviating neuropathic pain (e.g., weeks after injury; Suzuki et al., 2002; Rahman et al., 2006) but has no effect on maintenance of hyperalgesic priming? This may occur due to the unique pathophysiology of pain conditions that are dependent on persistent afferent drive such as peripheral nerve injury-induced neuropathic pain (Haroutounian et al., 2014). Therefore, pathological pain plasticity conditions that are dependent on central changes after an initial, but unsustained afferent barrage may be less susceptible to descending serotonergic modulation, indicating again that the cellular architecture underlying these conditions is likely unique.

While a broad line of evidence indicates that hyperalgesic priming involves plasticity in peripheral nociceptors (Reichling and Levine, 2009; Melemedjian et al., 2010; Ferrari et al., 2013; Wang et al., 2013; Melemedjian et al., 2014) and in the spinal dorsal horn (Asiedu et al., 2011; Melemedjian et al., 2013), the current findings point to a completely novel role for descending DA circuits in plasticity regulating a pathological state of pain plasticity. Further investigations into the role of $A 11$ and $D_{1} / D_{5}$ receptor-dependent plasticity in hyperalgesic priming will lead to a better understanding of the neurological architecture of this pathological pain state, which may lead to disease-modifying treatments for chronic pain.

\section{References}

Abdallah K, Artola A, Monconduit L, Dallel R, Luccarini P (2013) Bilateral descending hypothalamic projections to the spinal trigeminal nucleus caudalis in rats. PLoS One 8:e73022. CrossRef Medline

Abraham WC, Williams JM (2008) LTP maintenance and its protein synthesis-dependence. Neurobiol Learn Mem 89:260-268. CrossRef Medline

Aley KO, Messing RO, Mochly-Rosen D, Levine JD (2000) Chronic hypersensitivity for inflammatory nociceptor sensitization mediated by the epsilon isozyme of protein kinase C. J Neurosci 20:4680-4685. Medline

Asiedu MN, Tillu DV, Melemedjian OK, Shy A, Sanoja R, Bodell B, Ghosh S, Porreca F, Price TJ (2011) Spinal protein kinase M zeta underlies the maintenance mechanism of persistent nociceptive sensitization. J Neurosci 31:6646-6653. CrossRef Medline

Bardin L (2011) The complex role of serotonin and 5-HT receptors in chronic pain. Behav Pharmacol 22:390-404. CrossRef Medline

Becker S, Ceko M, Louis-Foster M, Elfassy NM, Leyton M, Shir Y, Schweinhardt P (2013) Dopamine and pain sensitivity: neither sulpiride nor acute phenylalanine and tyrosine depletion have effects on thermal pain sensations in healthy volunteers. PLoS One 8:e80766. CrossRef Medline

Bogen O, Alessandri-Haber N, Chu C, Gear RW, Levine JD (2012) Generation of a pain memory in the primary afferent nociceptor triggered by PKCepsilon activation of CPEB. J Neurosci 32:2018-2026. CrossRef Medline

Bolte S, Cordelières FP (2006) A guided tour into subcellular colocalization analysis in light microscopy. J Microsc 224:213-232. CrossRef Medline

Bonin RP, De Koninck Y (2014) A spinal analog of memory reconsolidation enables reversal of hyperalgesia. Nat Neurosci 17:1043-1045. CrossRef Medline

Brightwell JJ, Taylor BK (2009) Noradrenergic neurons in the locus coeruleus contribute to neuropathic pain. Neuroscience 160:174-185. CrossRef Medline

Brumovsky P, Villar MJ, Hökfelt T (2006) Tyrosine hydroxylase is expressed in a subpopulation of small dorsal root ganglion neurons in the adult mouse. Exp Neurol 200:153-165. CrossRef Medline

Chang PC, Pollema-Mays SL, Centeno MV, Procissi D, Contini M, Baria AT, Martina M, Apkarian AV (2014) Role of nucleus accumbens in neuropathic pain: linked multi-scale evidence in the rat transitioning to neuropathic pain. Pain 155:1128-1139. CrossRef Medline

Chapman CR, Casey KL, Dubner R, Foley KM, Gracely RH, Reading AE (1985) Pain measurement: an overview. Pain 22:1-31. CrossRef Medline

Charbit AR, Akerman S, Holland PR, Goadsby PJ (2009) Neurons of the dopaminergic/calcitonin gene-related peptide A11 cell group modulate neuronal firing in the trigeminocervical complex: an electrophysiological and immunohistochemical study. J Neurosci 29:12532-12541. CrossRef Medline

Charbit AR, Akerman S, Goadsby PJ (2011) Trigeminocervical complex responses after lesioning dopaminergic A11 nucleus are modified by dopamine and serotonin mechanisms. Pain 152:2365-2376. CrossRef Medline

Corder G, Doolen S, Donahue RR, Winter MK, Jutras BL, He Y, Hu X, Wieskopf JS, Mogil JS, Storm DR, Wang ZJ, McCarson KE, Taylor BK (2013) Constitutive mu-opioid receptor activity leads to long-term endogenous analgesia and dependence. Science 341:1394-1399. CrossRef Medline

Debiec J, LeDoux JE, Nader K (2002) Cellular and systems reconsolidation in the hippocampus. Neuron 36:527-538. CrossRef Medline

De Felice M, Sanoja R, Wang R, Vera-Portocarrero L, Oyarzo J, King T, Ossipov MH, Vanderah TW, Lai J, Dussor GO, Fields HL, Price TJ, Porreca $F$ (2011) Engagement of descending inhibition from the rostral ventromedial medulla protects against chronic neuropathic pain. Pain 152:2701-2709. CrossRef Medline

Dixon W (1965) The up-and-down method for small samples. J Am Stat Assoc 60:967-978.

Drdla-Schutting R, Benrath J, Wunderbaldinger G, Sandkühler J (2012) Erasure of a spinal memory trace of pain by a brief, high-dose opioid administration. Science 335:235-238. CrossRef Medline

Ferrari LF, Bogen O, Levine JD (2013) Role of nociceptor alphaCaMKII in transition from acute to chronic pain (hyperalgesic priming) in male and female rats. J Neurosci 33:11002-11011. CrossRef Medline

Fields HL, Heinricher MM, Mason P (1991) Neurotransmitters in nociceptive modulatory circuits. Annu Rev Neurosci 14:219-245. CrossRef Medline

Gao X, Zhang Y, Wu G (2001) Effects of dopaminergic agents on carrageenan hyperalgesia after intrathecal administration to rats. Eur J Pharmacol 418:73-77. CrossRef Medline

Goldstein DJ, Wang O, Todd LE, Gitter BD, DeBrota DJ, Iyengar S (2000) Study of the analgesic effect of lanepitant in patients with osteoarthritis pain. Clin Pharmacol Ther 67:419-426. CrossRef Medline

González-Burgos I, Feria-Velasco A (2008) Serotonin/dopamine interaction in memory formation. Prog Brain Res 172:603-623. CrossRef Medline

Hagelberg N, Forssell H, Aalto S, Rinne JO, Scheinin H, Taiminen T, Någren K, Eskola O, Jääskeläinen SK (2003a) Altered dopamine D2 receptor binding in atypical facial pain. Pain 106:43-48. CrossRef Medline

Hagelberg N, Forssell H, Rinne JO, Scheinin H, Taiminen T, Aalto S, Luutonen S, Någren K, Jääskeläinen S (2003b) Striatal dopamine D1 and D2 receptors in burning mouth syndrome. Pain 101:149-154. CrossRef Medline

Hansen N, Manahan-Vaughan D (2014) Dopamine D1/D5 receptors mediate informational saliency that promotes persistent hippocampal longterm plasticity. Cereb Cortex 24:845-858. CrossRef Medline

Haroutounian S, Nikolajsen L, Bendtsen TF, Finnerup NB, Kristensen AD, Hasselstrøm JB, Jensen TS (2014) Primary afferent input critical for maintaining spontaneous pain in peripheral neuropathy. Pain 155:12721279. CrossRef Medline

Hayashida K, Peters CM, Gutierrez S, Eisenach JC (2012) Depletion of endogenous noradrenaline does not prevent spinal cord plasticity following peripheral nerve injury. J Pain 13:49-57. CrossRef Medline

Hylden JL, Wilcox GL (1980) Intrathecal morphine in mice: a new technique. Eur J Pharmacol 67:313-316. CrossRef Medline

Janss AJ, Gebhart GF (1988) Brainstem and spinal pathways mediating descending inhibition from the medullary lateral reticular nucleus in the rat. Brain Res 440:109-122. CrossRef Medline

Jasper LL, MacNeil BJ (2012) Diverse sensory inputs permit priming in the acidic saline model of hyperalgesia. Eur J Pain 16:966-973. CrossRef Medline

Ji RR, Kohno T, Moore KA, Woolf CJ (2003) Central sensitization and LTP: do pain and memory share similar mechanisms? Trends Neurosci 26: 696-705. CrossRef Medline

Joseph EK, Parada CA, Levine JD (2003) Hyperalgesic priming in the rat demonstrates marked sexual dimorphism. Pain 105:143-150. CrossRef Medline

Kim YS, Chu Y, Han L, Li M, Li Z, Lavinka PC, Sun S, Tang Z, Park K, Caterina MJ, Ren K, Dubner R, Wei F, Dong X (2014) Central terminal 
sensitization of TRPV1 by descending serotonergic facilitation modulates chronic pain. Neuron 81:873-887. CrossRef Medline

Koltzenburg M, Wall PD, McMahon SB (1999) Does the right side know what the left is doing? Trends Neurosci 22:122-127. CrossRef Medline

Kostrzewa RM, Jacobowitz DM (1974) Pharmacological actions of 6-hydroxydopamine. Pharmacol Rev 26:199-288. Medline

Langford DJ, Bailey AL, Chanda ML, Clarke SE, Drummond TE, Echols S, Glick S, Ingrao J, Klassen-Ross T, Lacroix-Fralish ML, Matsumiya L, Sorge RE, Sotocinal SG, Tabaka JM, Wong D, van den Maagdenberg AM, Ferrari MD, Craig KD, Mogil JS (2010) Coding of facial expressions of pain in the laboratory mouse. Nat Methods 7:447-449. CrossRef Medline

Li Q, Lau A, Morris TJ, Guo L, Fordyce CB, Stanley EF (2004) A syntaxin 1, Galpha(o), and N-type calcium channel complex at a presynaptic nerve terminal: analysis by quantitative immunocolocalization. J Neurosci 24 : 4070-4081. CrossRef Medline

López-Avila A, Coffeen U, Ortega-Legaspi JM, del Angel R, Pellicer F (2004) Dopamine and NMDA systems modulate long-term nociception in the rat anterior cingulate cortex. Pain 111:136-143. CrossRef Medline

Lopez-Garcia JA (2006) Serotonergic modulation of spinal sensory circuits. Curr Top Med Chem 6:1987-1996. CrossRef Medline

Mantyh PW, Rogers SD, Honore P, Allen BJ, Ghilardi JR, Li J, Daughters RS, Lappi DA, Wiley RG, Simone DA (1997) Inhibition of hyperalgesia by ablation of lamina I spinal neurons expressing the substance P receptor. Science 278:275-279. CrossRef Medline

Melemedjian OK, Asiedu MN, Tillu DV, Peebles KA, Yan J, Ertz N, Dussor GO, Price TJ (2010) IL-6- and NGF-induced rapid control of protein synthesis and nociceptive plasticity via convergent signaling to the eIF4F complex. J Neurosci 30:15113-15123. CrossRef Medline

Melemedjian OK, Tillu DV, Asiedu MN, Mandell EK, Moy JK, Blute VM, Taylor CJ, Ghosh S, Price TJ (2013) BDNF regulates atypical PKC at spinal synapses to initiate and maintain a centralized chronic pain state. Mol Pain 9:12. CrossRef Medline

Melemedjian OK, Tillu DV, Moy JK, Asiedu MN, Mandell EK, Ghosh S, Dussor G, Price TJ (2014) Local translation and retrograde axonal transport of CREB regulates IL-6-induced nociceptive plasticity. Mol Pain 10:45. CrossRef Medline

Melzack R, Coderre TJ, Katz J, Vaccarino AL (2001) Central neuroplasticity and pathological pain. Ann N Y Acad Sci 933:157-174. Medline

Minett MS, Falk S, Santana-Varela S, Bogdanov YD, Nassar MA, Heegaard AM, Wood JN (2014) Pain without nociceptors? Nav1.7-independent pain mechanisms. Cell Rep 6:301-312. CrossRef Medline

Nichols ML, Allen BJ, Rogers SD, Ghilardi JR, Honore P, Luger NM, Finke MP, Li J, Lappi DA, Simone DA, Mantyh PW (1999) Transmission of chronic nociception by spinal neurons expressing the substance P receptor. Science 286:1558-1561. CrossRef Medline

Ossipov MH, Dussor GO, Porreca F (2010) Central modulation of pain. J Clin Invest 120:3779-3787. CrossRef Medline

Price TJ, Ghosh S (2013) ZIPping to pain relief: the role (or not) of PKMzeta in chronic pain. Mol Pain 9:6. CrossRef Medline

Price TJ, Inyang KE (2015) Commonalities between pain and memory mechanisms and their meaning for understanding chronic pain. In: Progress in molecular and translational science: molecular biology of pain (Price TJ, Dussor G, eds), pp 409-434. Oxford: Elsevier.

Rahman W, Suzuki R, Webber M, Hunt SP, Dickenson AH (2006) Depletion of endogenous spinal 5-HT attenuates the behavioural hypersensitivity to mechanical and cooling stimuli induced by spinal nerve ligation. Pain 123:264-274. CrossRef Medline

Reichling DB, Levine JD (2009) Critical role of nociceptor plasticity in chronic pain. Trends Neurosci 32:611-618. CrossRef Medline

Reichling DB, Green PG, Levine JD (2013) The fundamental unit of pain is the cell. Pain 154 [Suppl 1]:S2-S9. CrossRef

Roberts MH (1984) 5-Hydroxytryptamine and antinociception. Neuropharmacology 23:1529-1536. CrossRef Medline

Sawynok J, Reid A (1994) Spinal supersensitivity to 5-HT1, 5-HT2 and
5-HT3 receptor agonists following 5,7-dihydroxytryptamine. Eur J Pharmacol 264:249-257. CrossRef Medline

Sawynok J, Reid A, Nance D (1991) Spinal antinociception by adenosine analogs and morphine after intrathecal administration of the neurotoxins capsaicin, 6-hydroxydopamine and 5,7-dihydroxytryptamine. J Pharmacol Exp Ther 258:370-380. Medline

Schmidt EF, Kus L, Gong S, Heintz N (2013) BAC transgenic mice and the GENSAT database of engineered mouse strains. Cold Spring Harb Protoc 2013. CrossRef Medline

Shimizu T, Iwata S, Miyata A, Fukuda T, Nomoto M (2006) Delayed L-DOPA-induced hyperalgesia. Pharmacol Biochem Behav 85:643-647. CrossRef Medline

Sindrup SH, Graf A, Sfikas N (2006) The NK1-receptor antagonist TKA731 in painful diabetic neuropathy: a randomised, controlled trial. Eur J Pain 10:567-571. CrossRef Medline

Skagerberg G, Björklund A, Lindvall O, Schmidt RH (1982) Origin and termination of the diencephalo-spinal dopamine system in the rat. Brain Res Bull 9:237-244. CrossRef Medline

Song Z, Meyerson BA, Linderoth B (2011) Spinal 5-HT receptors that contribute to the pain-relieving effects of spinal cord stimulation in a rat model of neuropathy. Pain 152:1666-1673. CrossRef Medline

Suzuki R, Morcuende S, Webber M, Hunt SP, Dickenson AH (2002) Superficial NK1-expressing neurons control spinal excitability through activation of descending pathways. Nat Neurosci 5:1319-1326. CrossRef Medline

Suzuki R, Rygh LJ, Dickenson AH (2004a) Bad news from the brain: descending 5-HT pathways that control spinal pain processing. Trends Pharmacol Sci 25:613-617. CrossRef Medline

Suzuki R, Rahman W, Hunt SP, Dickenson AH (2004b) Descending facilitatory control of mechanically evoked responses is enhanced in deep dorsal horn neurones following peripheral nerve injury. Brain Res 1019:68-76. CrossRef Medline

Taniguchi W, Nakatsuka T, Miyazaki N, Yamada H, Takeda D, Fujita T, Kumamoto E, Yoshida M (2011) In vivo patch-clamp analysis of dopaminergic antinociceptive actions on substantia gelatinosa neurons in the spinal cord. Pain 152:95-105. CrossRef Medline

Teicher MH, Barber NI, Reichheld JH, Baldessarini RJ, Finklestein SP (1986) Selective depletion of cerebral norepinephrine with 6-hydroxydopamine and GBR-12909 in neonatal rat. Brain Res 395:124-128. CrossRef Medline

Tiemann L, Heitmann H, Schulz E, Baumkötter J, Ploner M (2014) Dopamine precursor depletion influences pain affect rather than pain sensation. PLoS One 9:e96167. CrossRef Medline

Tracey I, Mantyh PW (2007) The cerebral signature for pain perception and its modulation. Neuron 55:377-391. CrossRef Medline

Wang H, Heijnen CJ, van Velthoven CT, Willemen HL, Ishikawa Y, Zhang X, Sood AK, Vroon A, Eijkelkamp N, Kavelaars A (2013) Balancing GRK2 and EPAC1 levels prevents and relieves chronic pain. J Clin Invest 123: 5023-5034. CrossRef Medline

Wei H, Viisanen H, Pertovaara A (2009) Descending modulation of neuropathic hypersensitivity by dopamine D2 receptors in or adjacent to the hypothalamic A11 cell group. Pharmacol Res 59:355-363. CrossRef Medline

Wood PB, Schweinhardt P, Jaeger E, Dagher A, Hakyemez H, Rabiner EA, Bushnell MC, Chizh BA (2007) Fibromyalgia patients show an abnormal dopamine response to pain. Eur J Neurosci 25:3576-3582. CrossRef Medline

Yang HW, Zhou LJ, Hu NW, Xin WJ, Liu XG (2005) Activation of spinal $\mathrm{d} 1 / \mathrm{d} 5$ receptors induces late-phase LTP of C-fiber-evoked field potentials in rat spinal dorsal horn. J Neurophysiol 94:961-967. CrossRef Medline

Zhu H, Clemens S, Sawchuk M, Hochman S (2007) Expression and distribution of all dopamine receptor subtypes $(\mathrm{D}(1)-\mathrm{D}(5))$ in the mouse lumbar spinal cord: a real-time polymerase chain reaction and non-autoradiographic in situ hybridization study. Neuroscience 149:885-897. CrossRef Medline 